Adaptive Sports

\title{
Assessment of the upper limbs maximum power and the locomotion speed in amputee football players
}

\author{
${\text { Agnieszka M. } \text { Nowak }^{1} \text { (D), Angela Kwapis }}^{1}$ (D), Andrzej Kosmol ${ }^{1}$ \\ ${ }^{1}$ Akademia Wychowania Fizycznego Józefa Pitsudskiego, Wydziat Rehabilitacji, Warszawa, \\ Polska
}

Associate Editor: Angelina Zanesco, Departamento de Educação Física, Instituto de Biociências, Universidade Estadual Paulista "Júlio de Mesquita Filho", Rio Claro, SP, Brasil.

\begin{abstract}
Aim: The purpose of the study was to assess upper limbs' maximum power and locomotion speed among amputee football (amputee soccer) players. Methods: The 30-s Wingate Anaerobic test and the 20-m sprint test were performed. Anthropometric measurements and body composition (Body mass index (BMI), percentage of body fat (\% BF), and lean body mass (LBM)) were examined. Results: BMI significantly differentiated forwards and defenders ( $p$ $<0.05)$. Peak power (PP) and mean power (MP) were related to LBM $(p<0.05)$, thus defenders reached higher values of PP, in comparison to forwards. \% BF and BMI were related to relative mean power (rMP) $(p<0.05)$. Field position differentiated players in terms of upper limbs' relative peak power (rPP) in favour of forwards $(p<0.05)$. Age was a significant factor for speed velocity on $10 \mathrm{~m}$ and $20 \mathrm{~m}(p<0.05)$. There was no relationship between upper limbs' power and locomotion speed. Conclusion: Body composition, especially \% BF may influence on the anaerobic performance of amputee football players.
\end{abstract}

Keywords: upper extremities power, amputee soccer, anaerobic performance, lower limb loss, disabled athletes.

\section{Introduction}

Amputee football (AF) is becoming more and more popular all over the world especially in countries with a high percentage of traffic accidents and terrorist activities ${ }^{1}$. The game is a modification of able-bodied football, in which field players are people with lower limb disability, and goalkeepers are people whose upper limb is affected. Field players move on the pitch using crutches that are independently adjusted to every player and allow them to maintain balance and move $e^{2,3}$. This sport is characterized by highintensity short-term dynamic moves requiring the release of high values of power such as turns, accelerations and sprints, jumps, kicks, and ball control ${ }^{2}$. Therefore, AF requires from its participants high levels of anaerobic performance, muscular strength, balance, and locomotor abilities $^{4}$.

Sprinting (running fast in a straight line) is a key ability in AF. It was proved that not only the performance of lower limbs is important for sprinting by crutches, but also the performance of upper limbs ${ }^{4}$. Many actions in AF game, like in able-bodied football, are made after a few meters sprint. Analysis of the video of the first German National soccer league showed that $45 \%$ of goals were scored during a sprint along a straight line ${ }^{5}$. Others pointed to the importance of sprint velocity (the $10 \mathrm{~m}$ sprint) that was associated with the field position ${ }^{6}$. Studies indi- cated that field positions (forwards, midfielders, defenders) did not differ AF players according to velocity in the 20-m sprint, agility, endurance, body height, body weight, and body mass index (BMI). Only the percentage of body fat $(\% \mathrm{BF})$ differed players related to field position, and it was the lowest among the midfielders ${ }^{2}$. In Ozkan et al. ${ }^{4}$ study, correlations between body composition and 10, 20, $30 \mathrm{~m}$ sprints time among AF players had not been found but authors pointed that body composition played an important role in assessing anaerobic performance by countermovement jump (CMJ) and squat jump (SJ) in this group. In the same study, the authors indicated that sprint time was associated with power in $\mathrm{CMJ}$ and $\mathrm{SJ}^{4}$. Furthermore, players with crutches use between 10-30\% more energy in comparison to able-bodied athletes, which results in increased physical exertion. Moreover, decreased muscle mass in this group, involved in supporting and locomoting the body on crutches, impacts on peripheral fatigue $\mathrm{e}^{1-2}$. The research results are inconclusive, which prompted us to undertake research.

There are many para-sports, beside AF, in which upper limbs are important for efficient locomotion. In paracanoe, wheelchair basketball (WB) maximum power of upper limbs is a key ability. In paracanoe athletes cover the distance of $200 \mathrm{~m}$ within 40-60 $\mathrm{s}^{7}$ and the anaerobic processes predominate during this effort ${ }^{8}$. Athletes' performance depends on their functional possibilities that are 
determined by sport classes ${ }^{8-9}$. The study of anaerobic performance on groups of para-canoeists (LTA- move by extremities and trunk, A- move only by upper extremities) showed that the relative (rPP) and absolute maximum power (PP) values were significantly different between these sport classes in favour of the $\mathrm{LTA}^{9}$. A significant correlation between the rPP and PP between the sport classes was found.

Another sport in which effort is conditioned by the work of upper limbs is WB. This team sport contains many repeated short, intensive moves (e.g., accelerations and braking, dynamic changes position, maintain or gain position on a field) similarly to AF. In the study of Hutzler et al. ${ }^{10}$ high correlation between the players' classification and their mean power (MP) was found, and Vanlandewijck et al. ${ }^{11}$ have noticed that the performance on the basketball court mainly depends on anaerobic performance. It was also observed that WB players' maximum power (PP) of the upper limbs was to a certain extent related to their level of functional classification ${ }^{12}$ similarly to the results of the previously mentioned study 9 .

To conclude, the lack of extremity in the case of $\mathrm{AF}$ players may influence their anaerobic performance. It should be assumed that players need both lower and upper limb's power to perform sprints and efficient movement with crutches. No research has been found on the upper limb's power in short-term intensive efforts in AF. Thus, the purpose of this study was to assess upper limbs' maximum power and locomotion speed among AF players in accordance with field position, age, and body composition.

\section{Material and Methods}

\section{Participants}

Male AF players from the national league participated in this study; those with upper limb amputations were excluded to standardize the study group. Players were asked about the cause of amputation, training experience, and field position. Those who signed written consent were qualified for this study. All participants were informed about the benefits, risks of the investigation, and procedure before the study and about the option to withdraw their permission from the study without any repercussions. The local institutional review board (IRB) (SKE 01-53/2017) approved this study.

Eleven AF players with unilateral lower limb amputation participated and completed this study $(28.45 \pm 8.73$ yrs., $177.82 \pm 7.11 \mathrm{~cm}, 77.10 \pm 13.36 \mathrm{~kg}$ ), with training experience between two to seven years. Causes of amputation were traffic accidents $(\mathrm{n}=3)$, birth defects $(\mathrm{n}=2)$, fire accident $(\mathrm{n}=1)$, cancer $(\mathrm{n}=1)$, arterial hematoma $(\mathrm{n}=1)$ and burn's $(\mathrm{n}=1)$. Two of them chose not to disclose it. Participants were divided into groups of forwards and defenders. Midfielders were omitted because of the small group sample $(\mathrm{n}=2)$, and they were included in the defenders' group.

\section{Procedures}

Anthropometric measurements

In the beginning, body height and body weight measurements were carried out on a scale with a built-in height meter. The prostheses were removed for measurement. Body Mass Index (BMI) was calculated for every participant. Body components such as percentage of body fat (\% BF) and lean body mass (LBM) were estimated in near-infrared (NIR) spectroscopy by FUTREX 6100 (Futrex, Gaithersburg, USA) according to the procedures recommended by the manufacturer ${ }^{13}$. In this study authors used "body components" as a description of BMI, \%BF, and LBM.

Anaerobic performance assessment

The 30-s Wingate Anaerobic test (the WAnT) was performed on an arm-crank ergometer (LODE ANGIO, Groningen, Netherlands, Software Package-Wingate v.1.07b) to assess the anaerobic performance of upper $\operatorname{limbs}^{14}$. The ergometer was set on a wall-mounted gymnastic ladder in the laboratory. The test was performed in a sitting position on a special stand equipped with a seat. The ergometer axis was set individually to the level of the shoulder joints. Beforehand, athletes performed a 2-min warm-up on the ergometer and then 2-min rest. In the main test, participants were asked to work as fast as they can and perform this movement for $30 \mathrm{~s}$ with a $5.5 \%$ body weight load. During the test, participants were encouraged verbally to maximize their effort. Six parameters were measured during the WAnT such as peak power (PP) defined as the highest $5 \mathrm{~s}$ of power output, time to gain peak power (TimePP), mean power (MP) defined as the average power sustained throughout the $30 \mathrm{~s}$ period, relative peak power (rPP; scaled to individual body mass in kilograms), relative mean power (rMP; scaled to individual body weight in kilograms) and fatigue index (FI; the rate at which power declines).

\section{Locomotion speed assessment}

Participants performed the 20-m sprint test. To eliminate possible confounders, for instance, environmental factors, the sprint test was performed on the indoor sports hall with enough room to carry out the sprint test freely. Sprint time and velocity were measured by Microgate ${ }^{\circledR}$ photocells (electronic time measurement system with an accuracy of up to $0.01 \mathrm{~s}$; Bolzano, Italy) and Witty Manager software (version 1.4.1) ${ }^{15}$. Photocells were set on a $5 \mathrm{~m}, 10 \mathrm{~m}$, and $20-\mathrm{m}$ from the starting line. The starting position was standing with the whole body and crutches behind the starting line, awaiting the sound signal, and then they run as fast as they could. Participants performed 
the $20-\mathrm{m}$ sprint test twice. The best time of each participant was used for the final analysis. The distance was covered on crutches without the use of a prosthesis. All measurements and tests were performed within one day with complete rest between tests.

\section{Statistical analysis}

Statistical analysis was performed using program STATISTICA 12 StartSoft. Inc. The characteristics of the study group and test results were presented using the mean $(\bar{x})$, standard deviation (SD), median (M), minimum and maximum (min.-max.). The Shapiro-Wilk test was used to check the distribution of variables. The parametrical T-test and the non-parametrical U-Mann Whitney test were used to check differences between groups (forwards and defenders). The Pearson's correlation for normal distribution and the Spearman correlation for non-normal distribution were used to assess relationships between power, speed, age, and body composition. The level of statistical significance was set at $p<0.05$.

\section{Results}

Eleven AF players with unilateral lower limb amputation completed this study. In the group of AF players forwards had lower BMI and \% BF than defenders $(p<0.05)$. Forwards demonstrated a lower value of PP than defenders $(p>0.05)$, but forwards had significantly higher values of rPP than defenders $(p<0.05)$.

The results of the power and speed tests have proven that PP, MP, FI were higher in the defender's group with no statistical difference $(p>0.05)$. Other variables such as TimePP, rMP, rPP, and average results of the $20-\mathrm{m}$ sprint test in all distances $(5 \mathrm{~m}, 10 \mathrm{~m}, 20 \mathrm{~m})$ were in favor of the forwards, and rMP differentiated groups $(p<0.05)$. The detailed characteristics of the study group together with the results of the tests assessing power and speed, with division by the field positions are presented in Table 1 .

No significant relationship between the upper limb's power and locomotion speed was found (Table 2).

The analysis of the relationship between age, body composition, and power and speed is presented in Table 3. Players with higher BMI and higher \% BF achieved lower rMP values $(p<0.05)$. High correlations between LBM and PP and between LBM and MP were noted ( $p<0.05)$. Age was a significant factor for speed velocity on $10 \mathrm{~m}$ and $20 \mathrm{~m}(p<0.05)$ (Table 3$)$.

\section{Discussion}

The aim of this study was to assess upper limbs' maximum power and locomotion speed among AF players in accordance with field position, age, and body composition.

In this study, forwards had lower BMI and \% BF had higher rPP than defenders $(7.16$ and $6.60 \mathrm{~W} / \mathrm{kg}$, respectively). In WB and sitting volleyball (SV) players move using upper limbs. Some of the players can function on daily basis without a wheelchair, using crutches or prosthesis, like AF players. In comparison with the results achieved by WB and SV players (6.50 and $6.20 \mathrm{~W} / \mathrm{kg}$, respectively) ${ }^{16}$, forwards had higher values of $\mathrm{rPP}$, while similar results among defenders were noted. In the study on anaerobic performance in paracanoeing, it has also been proven that athletes represented sport classes such as LTA (usage of both upper limbs and lower limbs as well as their trunk) and A (only usage of upper limbs) were significantly higher in both relative and absolute power out-

Table 1 - Characteristic of the study group $(n=11)$ and results of the WAnT and the 20-m sprint test between forwards $(n=5)$ and defenders $(n=6)$.

\begin{tabular}{|c|c|c|c|c|c|c|}
\hline Variables & Field positions & $\bar{x} \pm \mathbf{S D}$ & $\mathbf{M}$ & Min. - Max. & Test & $p$ \\
\hline \multirow[t]{2}{*}{ Age [yrs.] } & $\mathrm{F}$ & $23.80 \pm 6.83$ & 20.00 & $17.00-33.00$ & $T$ & 0.109 \\
\hline & $\mathrm{D}$ & $32.33 \pm 8.69$ & 29.50 & $24.00-47.00$ & & \\
\hline \multirow[t]{2}{*}{ BMI $\left[\mathrm{kg} / \mathrm{m}^{2}\right]$} & $\mathrm{F}$ & $21.40 \pm 1.80$ & 21.65 & $18.40-23.28$ & $T$ & $0.004 *$ \\
\hline & $\mathrm{D}$ & $26.81 \pm 2.65$ & 26.30 & $23.14-31.12$ & & \\
\hline \multirow[t]{2}{*}{$\% \mathrm{BF}[\%]$} & $\mathrm{F}$ & $13.18 \pm 3.90$ & 12.50 & $9.50-19.50$ & $T$ & $0.026^{*}$ \\
\hline & $\mathrm{D}$ & $19.78 \pm 4.23$ & 18.60 & $14.70-25.80$ & & \\
\hline \multirow[t]{2}{*}{ LBM $[\mathrm{kg}]$} & $\mathrm{F}$ & $58.66 \pm 5.37$ & 61.70 & $52.50-63.80$ & $T$ & 0.068 \\
\hline & $\mathrm{D}$ & $67.75 \pm 8.47$ & 67.45 & $53.70-79.60$ & & \\
\hline \multirow[t]{2}{*}{$\mathrm{PP}[\mathrm{W}]$} & $\mathrm{F}$ & $484.00 \pm 45.86$ & 474.00 & $425.00-536.00$ & $T$ & 0.230 \\
\hline & $\mathrm{D}$ & $565.50 \pm 134.08$ & 589.00 & $363.00-716.00$ & & \\
\hline \multirow[t]{2}{*}{ TimePP [s] } & $\mathrm{F}$ & $8.00 \pm 2.70$ & 7.00 & $6.40-12.80$ & $U$ & 0.054 \\
\hline & $\mathrm{D}$ & $5.43 \pm 1.57$ & 6.00 & $3.40-7.20$ & & \\
\hline \multirow[t]{2}{*}{$\mathrm{MP}[\mathrm{W}]$} & $\mathrm{F}$ & $349.20 \pm 36.81$ & 352.00 & $305.00-401.00$ & $T$ & 0.538 \\
\hline & $\mathrm{D}$ & $369.67 \pm 62.78$ & 386.50 & $270.00-424.00$ & & \\
\hline
\end{tabular}


Table 1 - continued

\begin{tabular}{|c|c|c|c|c|c|c|}
\hline Variables & Field positions & $\bar{x} \pm \mathbf{S D}$ & $\mathbf{M}$ & Min. - Max. & Test & $p$ \\
\hline \multirow[t]{2}{*}{$\overline{\mathrm{rPP}}[\mathrm{W} / \mathrm{kg}]$} & $F$ & $7.16 \pm 0.30$ & 7.30 & $6.80-7.50$ & $T$ & 0.300 \\
\hline & $\mathrm{D}$ & $6.60 \pm 1.10$ & 6.65 & $5.00-8.00$ & & \\
\hline \multirow[t]{2}{*}{$\mathrm{rMP}[\mathrm{W} / \mathrm{kg}]$} & $\mathrm{F}$ & $5.18 \pm 0.43$ & 5.10 & $4.60-5.70$ & $T$ & $0.010^{*}$ \\
\hline & $\mathrm{D}$ & $4.35 \pm 0.41$ & 4.35 & $3.70-5.00$ & & \\
\hline \multirow[t]{2}{*}{$\mathrm{FI}[\mathrm{W} / \mathrm{s}]$} & $\mathrm{F}$ & $11.14 \pm 1.40$ & 11.30 & $9.20-13.10$ & $T$ & 0.137 \\
\hline & $\mathrm{D}$ & $15.12 \pm 5.24$ & 16.05 & $7.40-20.60$ & & \\
\hline \multirow[t]{2}{*}{$5 \mathrm{~m}[\mathrm{~m} / \mathrm{s}]$} & $\mathrm{F}$ & $3.86 \pm 0.55$ & 4.15 & $2.90-4.19$ & $T$ & 0.503 \\
\hline & $\mathrm{D}$ & $3.66 \pm 0.39$ & 3.69 & $3.01-4.22$ & & \\
\hline \multirow[t]{2}{*}{$10 \mathrm{~m}[\mathrm{~m} / \mathrm{s}]$} & $\mathrm{F}$ & $4.36 \pm 0.67$ & 4.52 & $3.25-4.95$ & $T$ & 0.290 \\
\hline & $\mathrm{D}$ & $4.00 \pm 0.38$ & 3.98 & $3.48-4.47$ & & \\
\hline \multirow[t]{2}{*}{$20 \mathrm{~m}[\mathrm{~m} / \mathrm{s}]$} & $\mathrm{F}$ & $4.83 \pm 0.86$ & 5.06 & $3.47-5.70$ & $T$ & 0.350 \\
\hline & D & $4.44 \pm 0.44$ & 4.53 & $3.90-5.02$ & & \\
\hline
\end{tabular}

$\bar{x}$ : mean; SD: standard deviation; M: median; min.: minimum value; max.: maximum value; F: forwards; D: defenders; BMI: Body Mass Index; \% BF: percentage of body fat; LBM: lean body mass; PP: peak power; MP: mean power; TimePP: time to gain peak power; rPP: relative peak power; rMP: relative mean power; FI: fatigue index; *: statistical significance $(p<0.05) ;{ }^{\mathrm{T}}$ : T-test; ${ }^{\mathrm{U}}$ : U-Mann Whitney test.

Table 2 - Correlation coefficient between the results of the WAnT and the results of the 20 -m sprint test $(n=11)$.

\begin{tabular}{|c|c|c|c|c|}
\hline \multicolumn{2}{|c|}{ Power variables } & \multicolumn{3}{|c|}{ Speed variables } \\
\hline & & $5 \mathrm{~m}[\mathrm{~m} / \mathrm{s}]$ & $10 \mathrm{~m}[\mathrm{~m} / \mathrm{s}]$ & $20 \mathrm{~m}[\mathrm{~m} / \mathrm{s}]$ \\
\hline $\mathrm{PP}[\mathrm{W}]$ & $\mathrm{r}$ & 0.224 & 0.097 & -0.003 \\
\hline TimePP [s] & $\mathrm{r}$ & 0.037 & -0.041 & -0.078 \\
\hline $\mathrm{MP}[\mathrm{W}]$ & $r$ & 0.233 & 0.048 & -0.065 \\
\hline $\mathrm{rPP}[\mathrm{W} / \mathrm{kg}]$ & $\mathrm{r}$ & 0.272 & 0.170 & 0.042 \\
\hline $\mathrm{rMP}[\mathrm{W} / \mathrm{kg}]$ & $\mathrm{r}$ & 0.090 & 0.024 & -0.061 \\
\hline FI [W/s] & $\mathrm{r}$ & 0.192 & 0.035 & -0.063 \\
\hline
\end{tabular}

PP: peak power; MP: mean power; TimePP: time to gain peak power; rPP: relative peak power; rMP: relative mean power; FI: fatigue index; *: statistical significance $(p<0.05)$.

comes in the WAnT, in favour to LTA athletes (PP: 590 and $343 \mathrm{~W}$ respectively; rPP: 7.99, $4.48 \mathrm{~W} / \mathrm{kg}$, respectively) ${ }^{9}$, that athletes are with more locomotor abilities $^{9,12,15}$.

The second analyzed parameter was locomotion speed (sprint performance). The forward sprint is the most frequent type of movement during amputee football match $^{17}$ and is described as being an essential factor in anaerobic performance ${ }^{4}$. Moreover, it is proven that body composition plays a significant role in sprint performan- $\mathrm{ce}^{4}$. In the current study, the relationship between body composition (BMI, \% BF, LBM) and upper limbs' power was found $(p<0.05)$ but there was no significant influence on sprint performance. In the literature, we cannot find studies comparing upper limbs PP and locomotion speed in AF. Referring to the lower limbs' maximum power assessment, a significant correlation between CMJ and sprint performance in AF players ${ }^{4}$ and in able-bodied athletes ${ }^{18}$ were found. It is indisputable that lower limbs' power is a key to locomotive abilities for able-bodied peo$\mathrm{ple}^{19}$. However, it has to be underlined that AF players make sprints using crutches and supporting their body on both upper limbs and intact limb during the match. It might be the reason for the lack of correlation between the WAnT and the 20-m sprint test in the current study. In terms of future possible studies relevant to the field, the analysis demonstrates a considerable need to focus on the assessment of the power of both upper and lower limbs.

In the present study, correlations between body composition and upper limbs' anaerobic performance, and between age and sprint performance were found. Simim et al. ${ }^{20}$ a study assessing muscular performance in relation to field position in $\mathrm{AF}$, no significant differences between field position and tests measuring power (CMJ, medicine ball throw) and muscle endurance (push-ups) were found.

Table 3 - Correlation coefficient between age, body composition, and between results of the WAnT and the velocity in 20-m sprint test ( $\mathrm{n}=11)$.

\begin{tabular}{|c|c|c|c|c|c|c|c|c|c|c|}
\hline Variables & & PP [W] & TimePP [s] & MP [W] & $\mathrm{rPP}[\mathrm{W} / \mathrm{kg}]$ & rMP [W/kg] & FI $[W / s]$ & $5 \mathrm{~m} \mathrm{[m/s]}$ & $10 \mathrm{~m}[\mathrm{~m} / \mathrm{s}]$ & $20 \mathrm{~m}[\mathrm{~m} / \mathrm{s}]$ \\
\hline Age [yrs.] & $\mathrm{r}$ & 0.393 & 0.039 & 0.377 & 0.217 & -0.055 & 0.519 & -0.482 & $-0.664 *$ & $-0.669 *$ \\
\hline BMI $\left[\mathrm{kg} / \mathrm{m}^{2}\right]$ & $\mathrm{r}$ & 0.594 & $-0.699 *$ & 0.446 & -0.304 & $-0.759^{*}$ & $0.605^{*}$ & -0.004 & -0.120 & -0.087 \\
\hline$\% \mathrm{BF}[\%]$ & $\mathrm{r}$ & 0.425 & $-0.690 *$ & 0.246 & -0.399 & $-0.787 *$ & 0.435 & -0.047 & -0.087 & -0.009 \\
\hline LBM $[\mathrm{kg}]$ & $\mathrm{r}$ & $0.880^{*}$ & -0.589 & $0.809 *$ & 0.121 & -0.388 & $0.812 *$ & 0.109 & 0.013 & -0.071 \\
\hline
\end{tabular}

\% BF: percentage of body fat; LBM: lean body mass; PP: peak power; MP: mean power; TimePP: time to gain peak power; rPP: relative peak power; rMP: relative mean power; FI: fatigue index; *: statistical significance $(p<0.05)$. 
Ozkan et al. ${ }^{4}$ recognized the results of the present study in terms of anaerobic performance (power) but it is in opposition to these results in terms of sprint performance. Differences in studies' results can be present because in one study different methods were used (CMJ, medicine ball throw, and push-ups) ${ }^{20}$. In another study differences between results in locomotion speed mostly can be present because of differences in study groups ${ }^{4}$. In the current study, players were older (28.45 yrs. vs. 25.5 yrs.) and had higher body weight $(77.10 \mathrm{~kg}$ vs. $66.50 \mathrm{~kg})$. Moreover, authors used CMJ to assess lower limbs' power ${ }^{4}$ and in the current study, the WAnT was used to assess the upper limb's power. Additionally, both Simim et al. and Ozkan et al. in the study groups were players from national team $^{4,20}$ while AF players from the national league were recruited for the current study. It is important for subsequent analyses on the influence of age and body composition on locomotion speed in AF players.

It had been noted that forwards had lower body weight, higher body height, and were younger age than defenders, which might influence their physical predispositions (because of higher values of potential rPP). It is consistent with the results of the Simim et al. ${ }^{2}$ study. However, the authors set three field positions (defenders, midfielders, and forward) in contrast to the present study (defenders and forwards), and among them the lowest body weight and the highest were midfielders ${ }^{2}$. Innocencio da Silva Gomes et al. ${ }^{21}$ presented opposite findings according to which midfielders were the heaviest and had the highest \% BF, and defenders were the highest, and forward had the lowest body weight. Those differences may be attributed to group samples, which might be not representative because of the minor sample size Turkish $^{2} n=$ 12 , Brazilian ${ }^{21} \mathrm{n}=15$ ). Based on this assumption, we cannot predict how the parameters are placed in the overall AF population. To the best of our knowledge, this study is the first one concerning AF, field position, anaerobic performance, and locomotion speed, which does not allow us to compare obtained results with other studies. In future studies, more AF players should be recruited to the study, with division by playing position and taking into account level of amputation and age of players.

\section{Limitations and perspectives}

Assessing players with valid and standardized laboratory tests is in the authors opinion a great value of this work. It is worth underlining that AF players use both upper and lower limbs to move and are use crutches. This specificity of movement is unique in sport; therefore, authors think that in the future study it will be important to assess anaerobic performance both for upper and for lower limbs. It allows to understand well the significance of upper and lower limbs in this specific movement pattern and gives coaches hints and pointers to prepare their players better. Study on the highest-level AF players can allow gaining a better understanding of the influence of anaerobic performance in the pitch, and next analyze these parameters with for example game performance in accordance with field positions. AF is a relatively young discipline, so the fact that there have been merely few studies in the field is entirely understandable. It was noted that researchers tried assessing AF players in different parts of the world and dwelled in different areas but most of them focused on studying one team that gives 10 to 15 participants (number of participants) was also a limitation of the current study. The next limitation was not to consider the level of lower limb amputation and muscle strength that could scientifically impact speed abilities. Further research on both anaerobic and aerobic performance in AF players can help people working with them to further develop the understanding of the physical consequences after amputation and the abilities of players, and further effort to develop training programs that would be better adjusted.

\section{Practical implications}

In this study, participants were assessed by a valid and standardized laboratory test (the 30-s Wingate test) that is in the authors opinion a great value of this work. AF as a PA or sport activity might be a continuation of the rehabilitation process that is particularly long in the amputee population. In this study, authors suggested that $\% \mathrm{BF}$ may influence anaerobic performance in AF players which in turn indicates the health aspect. Moreover, upper limbs' power is an important indicator in the daily mobility of people using crutches and can help in daily life activities in general. Additionally, coaches should take into consideration that maximum power may differentiate players depending on their field position, that can be important in the context of team building and improving technical and tactical skills.

\section{Conclusions}

In conclusion, upper limbs' maximum power among AF players in comparison to other athletes functionally similar in WB and SV are comparable and have a mostly higher value. Body composition, especially \% BF may influence the anaerobic performance of AF players. Field positions differentiate players in terms of rPP, in favour of forwards. Upper limbs' power may not be the key factor in locomotion speed in AF because of no clear results showing a relationship between these parameters.

\section{Acknowledgments}

The authors wish to thank the participants for their invaluable contribution to the study. This work was supported by the Ministry of Education and Science in the year 2021 under Research Group no 4 at Jozef Pilsudski University 
of Physical Education in Warsaw "Physical activity and sports for people with special needs".

\section{References}

1. Simim MAM, da Mota GR, Marocolo M, da Silva BVC, de Mello MT, Bradley PS. The demands of amputee soccer impair muscular endurance and power indices but do not match physical performance. Adapt Phys Activ Q. 2018;35 (1):76-92. DOI:10.1123/apaq.2016-0147.

2. Simim MAM, Silva BVC, Marocolo Júnior M, Mendes EL, de Mello MT, da Mota GR. Anthropometric profile and physical performance characteristic of the Brazilian amputee football (soccer) team. Motriz: Rev. Educ. Fis. 2013;19 (3):641-8. DOI:10.1590/s1980-65742013000300016.

3. Frere J. The History of "modern" Amputee Football. In: Amputee Sports for Victims of Terrorism. Ankara, IOS Press; 2007. p. 5-13.

4. Ozkan A, Kayıhan G, Koklu Y, Ergun N, Koz M, Ersoz G, et al. The relationship between body composition, anaerobic performance, and sprint ability of amputee soccer players. J Hum Kinet. 2012;35:141-6. DOI:10.2478/v10078-0120088-3.

5. Faude O, Koch T, Meyer T. Straight sprinting is the most frequent action in goal situations in professional football. $\mathrm{J}$ Sports Sci. 2012;30(7):625-31. DOI:10.1080/ 02640414.2012 .665940$.

6. Ferro A, Villacieros J, Floría P, Graupera JL. Analysis of speed performance in soccer by a playing position and a sports level using a laser system. J Hum Kinet. 2014;44:143-53. DOI:10.2478/hukin-2014-0120.

7. van Someren KA, Palmer GS. Prediction of 200-m sprint kayaking performance. Can J Appl Physiol. 2003;28 (4):505-17. DOI:10.1139/h03-039.

8. Zamparo P, Capelli C, Guerrini G. Energetics of kayaking at submaximal and maximal speeds. Eur J Appl Physiol Occup Physiol. 1999;80(6):542-8. DOI:10.1007/s004210050632.

9. Starczewski M, Molik B. Selected anaerobic capacity parameters regard to paracanoe functional classification. Advances in Rehabilitation. 2014;28(1):31-5. DOI:10.2478/rehab2014-0031.

10. Hutzler Y. Physical performance of elite wheelchair basketball players in arm cranking ergometry and selected wheeling tasks. Paraplegia. 1993;31(4):255-61. DOI:10.1038/ sc. 1993.45 .

11. Vanlandewijck Y, Goris M, Verstuyft J. Performance evaluation in wheelchair athletes: A sport-specific, multidisciplinary approach'. In: Second European Conference on adapted physical activity and sports: Health, well-being, and employment. Leuven, Acco; 1996. p. 185-94.

12. Molik B, Laskin JJ, Kosmol A, Skucas K, Bida U. Relationship between functional classification levels and anaerobic performance of wheelchair basketball athletes. Res Q Exerc Sport. 2010;81(1):69-73. DOI:10.1080/ 02701367.2010 .10599629 .
13. Fukuda DH, Wray ME, Kendall KL, Smith-Ryan AE, Stout JR. Validity of near-infrared interactance (FUTREX 6100/ $\mathrm{XL}$ ) for estimating body fat percentage in elite rowers. Clin Physiol Funct Imaging. 2017;37(4):456-8. DOI:10.1111/ cpf. 12328 .

14. Inbar O, Bar-Or O, Skinner J. The Wingate Anaerobic Test. Ed. Campaign, Human Kinetics, 1996.

15. Marszałek J, Kosmol A, Morgulec-Adamowicz N, Mróz A, Gryko K, Skucas K, et al. Laboratory and non-laboratory assessment of the anaerobic performance of elite male wheelchair basketball athletes. Front Psychol. 2019;10:514. DOI:10.3389/fpsyg.2019.00514.

16. Kosmol A, Molik B, Morgulec N, Nowicki T. Poziom wydolnosci beztlenowej osób niepełnosprawnych w wybranych dyscyplinach sportu. In: Kierunki doskonalenia treningu i walki sportowej. Warsaw, Jozef Pilsudski University of Physical Education; 2003. p. 277-82.

17. Goktepe AS. Energy Systems in Sports. In: Amputee Sports for Victims of Terrorism. Ankara, IOS Press; 2007. p. 2431.

18. Cronin JB, Hansen KT. Strength and power predictors of sports speed. J Strength Cond Res. 2005;19(2):349-57. DOI:10.1519/14323.1.

19. Kin-Isler A, Arıburun B, Ozkan A, Aytar A, Tandogan RN. The relationship between anaerobic performance, muscle strength, and sprint ability in American football players. Isokinetic Exerc Sci. 2008;16(2):87-92. DOI:10.3233/IES2008-0301.

20. Simim MA, Bradley PS, da Silva BV, Mendes EL, de Mello MT, Marcolo M, et al. The quantification of game-induced muscle fatigue in amputee soccer players. J Sports Med Phys Fitness. 2017;57(6):766-72. DOI:10.23736/S00224707.16.06299-X.

21. Innocencio da Silva Gomes A, Ribeiro BG, de Abreu Soares E. Nutritional profile of the Brazilian Amputee Soccer Team during the precompetition period for the world championship. Nutrition. 2006;22(10):989-95. DOI:10.1016/j. nut.2006.05.019.

\section{Corresponding author}

Agnieszka M. Nowak, Jozef Pilsudski University of Physical Education, Faculty of Rehabilitation, Marymoncka 34 Street, 00-968 Warsaw, Poland. E-mail: agnieszka.nowak@awf.edu.pl.

Manuscript received on January 20, 2021 Manuscript accepted on March 23, 2021

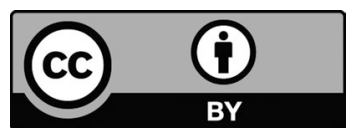

Motriz. The Journal of Physical Education. UNESP. Rio Claro, SP, Brazil - eISSN: 1980-6574 - under a license Creative Commons - Version 4.0 